\title{
Neuroaxonal Dystrophy
}

National Cancer Institute

\section{Source}

National Cancer Institute. Neuroaxonal Dystrophy. NCI Thesaurus. Code C161542.

A finding that refers to the axonal swelling (spheroids) located throug hout the central and peripheral nervous system. 